\title{
Painful osteoporotic vertebral fractures and vertebroplasty: where is the black swan?
}

\author{
AP Toms \\ Consultant Radiologist, Norwich Radiology Academy, Cotman Centre, Norwich, UK
}

TITLE Vertebroplasty versus conservative treatment in acute osteoporotic vertebral compression fractures (Vertos II): an open-label randomised trial.

AUTHORS Klazen C, Lohle P, de Vries J et al.

JOURNAL Lancet 20I0; 376:1085-92. doi:I0.1016/S0I40-6736(I0)60954-3

DECLARATION OF INTERESTS No conflict of interests declared.

\author{
Correspondence to AP Toms, \\ Norwich Radiology Academy, \\ Cotman Centre, Colney Lane, \\ Norwich NR4 7UB, UK \\ tel. $+44(0) 1603286143$ \\ e-mail andoni.toms@nnuh.nhs.uk
}

\section{SUMMARY}

Vertebroplasty, the percutaneous injection of polymethylmethacrylate cement into vertebral bodies, has been described for at least 14 years. It has become a standard of care for the treatment of painful osteoporotic vertebral fractures, particularly in many centres in the US, where there are approximately 750,000 new vertebral fractures a year. Vertebroplasty is believed by its many advocates to bring effective pain relief, probably by stabilising the fracture site.

This was a randomised trial comparing vertebroplasty with conservative treatment for painful osteoporotic fractures less than six weeks old. Inclusion criteria included vertebral compression on plain radiographs, bone marrow oedema on magnetic resonance imaging, focal tenderness of the spinal process corresponding to the radiographic changes and pain on a visual analogue scale (VAS) of 5 or more. A total of 101 patients were allocated to vertebroplasty and $\mathrm{IOI}$ to conservative therapy. Both groups underwent the same pain management regime.

Vertebroplasty was demonstrated to be significantly more effective at reducing pain acutely (VAS difference 2.6) and up to one year after treatment (VAS difference 2.0). Side effects of treatment were not thought to be significant and the cost of vertebroplasty was calculated at approximately $£ 26,600$ per quality-adjusted life year gained.

\section{OPINION}

This paper comes exactly one year after publication, in the New England Journal of Medicine, of two randomised placebo-controlled trials (RCT) of vertebroplasty for painful osteoporotic vertebral fractures. ${ }^{1,2}$ Neither of these studies was able to demonstrate a statistically significant difference between patients treated with vertebroplasty or a sham procedure. It was concluded by the authors that 'it therefore seems inappropriate to offer this treatment in routine care'. ${ }^{3}$
Supporters of vertebroplasty were quick to identify a number of limitations in the study designs. These included problems and delays in recruiting, leading to early closure of one study, relatively small numbers of participants (illustrated by the wide confidence intervals in both studies) and the possibility of selection bias. ${ }^{4}$ The argument was that the choice between an apparently established treatment, vertebroplasty, and a clinical trial which might mean no effective treatment is likely to select out the most symptomatic patients.

The Vertos II study is not without limitations. It is not a placebo-controlled trial and there is therefore still doubt about the mechanism of the effect. But there is clearly a pragmatic effect and, unlike the RCTs, this study is undoubtedly adequately powered with more clearly defined early fractures with higher pain scores.

Where does this leave patients, radiologists and health service commissioners? We have two studies heroically upholding the purity of the RCT, albeit with contested outcomes, advocating at least a moratorium on vertebroplasty, and one robust randomised trial, without placebo, supporting vertebroplasty for acutely painful fractures.

We might do well to remember Karl Popper and his black swans. ${ }^{5}$ The two RCTs were designed to test the null hypothesis that there was no difference between the treatment and placebo groups and they failed to disprove this null hypothesis. It does not therefore follow that the null hypothesis has been proven to be true. However, their results, and the results of the Vertos II study, do suggest that, at the very least, patient selection may be critical if vertebroplasty is to be found to be effective.

Two outcomes are still possible. Vertebroplasty may be a useful tool that improves the quality of life in patients with painful osteoporotic fractures or it may be an expensive and ineffective intervention. For the moment it would seem that there is enough evidence to support vertebroplasty in carefully selected and consented patients, on a case by case basis, but more evidence will be required to support vertebroplasty in standard healthcare pathways. 


\section{REFERENCES}

I Buchbinder R, Osborne RH, Ebeling PR et al. A randomized trial of vertebroplasty for painful osteoporotic vertebral fractures. N Engl J Med 2009; 361:557-68. doi: 10.1056/NEJMoa0900429

2 Kallmes DF, Comstock BA, Heagerty PJ et al. A randomized trial of vertebroplasty for osteoporotic spinal fractures. N Engl J Med 2009; 361:569-79. doi: I0.1056/NEJMoa0900563

3 Buchbinder R, Kallmes DF. Vertebroplasty: when randomized placebo-controlled trial results clash with common belief. Spine J 2010; 10:24I-3. doi:10.1016/j.spinee.2010.01.001
4 Clark W, Lyon S, Burnes J et al. Trials of vertebroplasty for vertebral fractures. N Engl J Med 2009; 361:2097. doi:10.1056/ NEJMc096289

5 Popper K. A survey of some fundamental problems. In: The logic of scientific discovery. New York: Basic Books; 1959. p. 27.

\section{EVENING MEDICAL UPDATES: 20I I}

Open to all medical personnel. Evening Medical Updates start at $6.30 \mathrm{pm}$ and close at approximately $8.15 \mathrm{pm}$.

\begin{tabular}{lr} 
a Jaundice & 25 January 2011 \\
\hline Weakness/paralysis & 22 February 2011 \\
\hline - Palpitations & 22 March 2011 \\
\hline Vomiting/Nausea & 26 April 2011 \\
\hline Headache & 24 May 2011 \\
\hline Haematemesis/melaena & 21 June 2011 \\
\hline
\end{tabular}

Full programme and details at http://events.rcpe.ac.uk
Evening Medical Updates are also webstreamed live and video-linked to sites throughout the UK. Check online to see if there is a venue near you, or email a.fairbairn@rcpe.ac.uk if you are interested in live webstreaming or your hospital video-linking into the EMU programme of events.

For further information please contact: Mrs Anne Fairbairn, Education, Training \& Standards Department, Royal College of Physicians of Edinburgh, 9 Queen Street, Edinburgh EH2 IJQ Tel: 0I3। 2473649

Fax: 01312204393

E-mail: a.fairbairn@rcpe.ac.uk 